\title{
Escravidão "suave” no Brasil: Gilberto Freyre tinha razão?
}

\author{
FLÁVIO RABELO VERSIANI*
}

"Soft" slavery in Brazil: was Gilberto Freyre right? This article examines the question of the supposedly benign character of Brazilian slavery in contrast with North America slavery. In economic analyses of slavery, coercion toward slaves is viewed as a means to achieve maximum output, especially in large-scale agriculture. In small slave holdings, however, coercion was generally inefficient for that purpose, and positive incentives tended to be preferred. It is argued that, as recent evidence on Brazil has shown that small slave holdings prevailed in various regions and periods, this may lend empirical support to the notion of a relatively benign slavery, using more incentives than coercion.

Key-words: slave work; Brazil: slavery; Brazil: XIX century

JEL Classification: N36

\section{INTRODUÇÃO}

A idéia de que a escravidão no Brasil era em geral mais benigna do que em outras partes do Novo Mundo remonta pelo menos ao século XVIII, e tem despertado extensa controvérsia. As argumentações sobre o tema na literatura em geral têm pouca base empírica e costumam centrar-se no jogo de interesses que estaria associado à difusão daquela interpretação. Vários autores consideraram a tese da benignidade uma mera expressão da ideologia das camadas dominantes no século XIX; sua divulgação, especialmente no exterior, faria parte dos esfor-

\footnotetext{
* Departamento de Economia, Universidade de Brasília. E-mail: versiani@unb.br. Submetido: outubro 2005; aceito abril 2006. O artigo beneficiou-se de comentários a versões anteriores feitos por Eustáquio Reis, Stephen de Castro, Yony Sampaio, Luiz Noguerol, José Vergolino e um parecerista anônimo desta Revista, a quem o autor agradece, isentando-os de responsabilidade pelo produto final. A pesquisa de que o artigo é parte recebeu apoio do PRONEX/FAP-DF/CNPq e do PROCAD/CAPES. O autor é bolsista do CNPq.
} 
ços do governo imperial no sentido de disseminar uma imagem amena da escravidão e, com isso, contrapor-se ao movimento abolicionista.

A dificuldade de obter evidência empírica sobre a questão é evidente: depende-se de testemunhos de contemporâneos, e a fidedignidade ou representatividade destes pode ser posta em dúvida. Por outro lado, algumas indicações sobre a forma de tratamento dos escravos podem ser derivadas da análise econômica do escravismo. Sob essa perspectiva, um tratamento coercitivo pode ser visto, em certas circunstâncias, como a opção "racional" dos senhores de escravos, tendo em vista o objetivo de maximizar a produção; em outras circunstâncias, no entanto, será preferível usar não a coerção, mas alguma forma de incentivo positivo. Assim, o exame da ocorrência histórica de um ou outro tipo de circunstâncias pode dar pistas sobre a maior ou menor utilização da coação física para com os cativos. Ou seja, da menor ou maior "benignidade" da escravidão.

Este artigo ressalta dois pontos. Primeiro, a relevância da abordagem econômica no contexto do debate sobre o tratamento de escravos no Brasil. Segundo, o fato de que, como mostram pesquisas recentes, a ocorrência de circunstâncias favoráveis à utilização de métodos não-coercitivos teria sido, no caso brasileiro, mais comum do que se costumava supor. Nesse sentido, pode-se argumentar que a evidência histórica tende a dar certo apoio à idéia de uma escravidão relativamente benigna no Brasil.

A próxima seção trata da tese da benignidade e seus antecedentes. Em seguida, examina-se a relação entre coerção e maximização de produção na literatura econômica do escravismo. A quarta seção refere a argumentação econômica às idéias do mais conhecido expositor da tese da benignidade entre nós, Gilberto Freyre. A seção seguinte trata de algumas características relevantes da escravidão brasileira descritas na literatura recente; e a última seção reúne as conclusões do artigo.

\section{A TESE DA BENIGNIDADE}

A crença de que o tratamento de escravos fosse mais brando por parte de portugueses vem desde o século XVIII. "The Spaniards and Portuguese had the widespread reputation by the eighteenth century-whatever may have been the reasons-for being among all nations the best masters of slaves" (Elkins, 1976:77). Para Wadström, figura influente do movimento abolicionista europeu no final desse século, os portugueses e espanhóis, além dos dinamarqueses, seriam os melhores senhores de escravos, enquanto os ingleses e holandeses seriam os piores. ${ }^{1}$

No século XIX, a fonte mais conhecida do argumento são os depoimentos de viajantes estrangeiros que percorreram o Brasil, especialmente depois da aber-

${ }^{1}$ Wadström (em An Essay on Colonization, publicado em 1794), apud Elkins (1976:77). 
tura dos portos, em 1808. Como se sabe, foram numerosos os relatos publicados, na Europa e nos Estados Unidos, por tais cronistas. Menções de um tratamento brando de escravos são freqüentes nesses escritos, muitas vezes com mostras de surpresa. Um bom exemplo são os relatos de viagem de Saint-Hilaire, naturalista francês que veio ao Brasil em 1816, na comitiva do Duque de Luxemburgo, e aqui permaneceu até 1822 , pesquisando nossa flora. Para isso, viajou extensamente pelo Centro-Sul do País, desde Minas e Goiás à então Província Cisplatina, cerca de quinze mil quilômetros em lombo de cavalo. No primeiro de seus cinco livros de viagem, publicado na França em 1830, escreveu:

"No estado atual das coisas, devemos, para ser justos, fazer concessões aos partidários da escravidão. O negro que cai nas mãos de um senhor bom e sinceramente cristão é, devemos confessá-lo, mais feliz do que a maioria dos camponeses de certas províncias da França; trabalha muito menos; não tem as mesmas inquietações; a fome e a miséria não o ameaçam constantemente; vivendo num clima quente, tem poucas necessidades, e aquilo de que carece o senhor lhe dá (...).” (Saint-Hilaire, 1975[1830]:54).

Referências análogas aparecem nos seus outros relatos (Versiani, 2000). No último que publicou em vida (há um volume póstumo), mais de vinte anos depois, foi ainda mais enfático:

"Todo mundo sabe, de resto, que os brasileiros tratam geralmente os escravos com grande brandura. A esse propósito podem ser consultados os trabalhos de Gardner ("Travels") e mais recentemente os de Blumenau ("Süd brazilien”); finalmente, o que eu próprio escrevi (...)." (Saint-Hilaire, 1978[1851]:173 n.365).

Outro exemplo é o de Sir Richard Burton, famoso explorador e escritor inglês, cônsul em Santos de 1865 a 1868, que publicou um minucioso relato de sua viagem de vários meses pela região das minas, em 1867, seguida de uma jornada de barco, no Rio das Velhas e no São Francisco, desde Sabará até a Cachoeira de Paulo Afonso. Sobre o ponto que nos interessa, opinou:

"Não me demorarei em discutir se a raça ou o clima, a religião ou a situação da sociedade, ou todos esses fatores combinados, são os responsáveis pelo tratamento excepcionalmente humano que o escravo recebe no Brasil; posso, contudo, assegurar que, em nenhuma outra terra, nem mesmo nos países orientais, uma 'gota tão amarga' contém tão pouco fel. Minha experiência nunca revelou um caso de crueldade praticado contra os escravos, e somente ouvi falar de alguns poucos casos de flagelação severa. (...) Atualmente, o negro brasileiro não precisa inve- 
jar a liberdade esfomeada dos pobres na maior parte do mundo civilizado." (Burton, 1976[1869]:233).

A crença em uma escravidão relativamente branda era, ao que parece, bastante difundida no País, no século XIX. Como assinalou Joaquim Nabuco, com sarcasmo, em O Abolicionismo:

"Em qualquer número de um grande jornal brasileiro (...) encontram-se (...) declarações repetidas de que a escravidão entre nós é um estado muito brando e suave para o escravo, de fato melhor para este do que para o senhor, tão feliz pela descrição, que se chega a supor que os escravos, se fossem consultados, prefeririam o cativeiro à liberdade." (Nabuco, 1988[1883]:95-96).

Mas o próprio Nabuco produziu, anos mais tarde, em sua autobiografia, algumas das passagens mais eloqüentes sobre o caráter ameno que as relações entre senhores e escravos podiam assumir, no Brasil. Em suas recordações de infância, a escravidão lhe aparecia como "um jugo suave, orgulho exterior do senhor, mas também orgulho íntimo do escravo, alguma coisa parecida com a dedicação do animal que nunca se altera porque o fermento da desigualdade não pode penetrar nela". (Nabuco, 2001[1900]:183-184). E escreveu ainda, poeticamente (num trecho recentemente musicado por Caetano Veloso):

"[A escravidão] espalhou por nossas vastas solidões uma grande suavidade; [....] ela povoou [o País] como se fosse uma religião natural e viva, com seus mitos, suas legendas, seus encantamentos; insuflou-lhe sua alma infantil, suas tristezas sem pesar, suas lágrimas sem amargor, seu silêncio sem concentração, suas alegrias sem causa, sua felicidade sem dia seguinte... É ela o suspiro indefinível que exalam ao luar as nossas noites do Norte. Quanto a mim, absorvi-a no leite preto que me amamentou; ela envolveu-me como uma carícia muda toda a minha infância; aspireia da dedicação de velhos servidores que me reputavam o herdeiro presuntivo do pequeno domínio de que faziam parte... " (ibid.: 183). ${ }^{2}$

A noção de uma natureza diferencial, relativamente benigna, da escravidão brasileira foi subscrita, antes e depois da Abolição, por vários outros cronistas e historiadores de destaque, como Couty, Oliveira Lima e Roberto Simonsen. ${ }^{3}$

Mas foi em Gilberto Freyre que essa idéia ganhou sua expressão mais conhecida e influente. Já em sua tese de mestrado, apresentada em 1922 nos Estados Unidos, ele afirmava:

\footnotetext{
${ }^{2}$ Cf.: Caetano Veloso, Noites do Norte, Mercury Records.

${ }^{3}$ Couty (1988[1881]:52 e ss.); Oliveira Lima (1997[1895]:246 e ss.); Simonsen (1977[1937]:143).
} 
"Na verdade, a escravidão no Brasil agrário-patriarcal pouco teve de cruel. O escravo brasileiro levava, nos meados do século XIX, quase vida de anjo, se compararmos sua sorte com a dos operários ingleses, ou mesmo com a dos operários do continente europeu, dos mesmos meados do século passado." (Freyre, 1964[1922]:98).

$\mathrm{Na}$ década seguinte, Freyre elaborou de vários modos essa noção em seus livros mais conhecidos, inclusive estendendo-a no tempo ("[No Brasil] a escravidão parece ter sido desde o século XVI mais benigna para o escravo do que na América inglesa"). Onde predominava uma postura "patriarcal" por parte dos senhores -, o que, para Freyre, ocorrera principalmente no Nordeste açucareiro, nas fazendas de café do Rio de Janeiro, nas estâncias sulinas e em áreas urbanas correspondentes - prevalecia "a doçura no tratamento de escravos"; estes teriam sido, "entre os brasileiros (...), mais gente de casa do que besta de trabalho". Aos modos benévolos dos senhores corresponderia, da parte dos escravos, uma atitude de cooperação ("o sistema patriarcal [era], a seu modo, cooperativo") ou, pelo menos, conformista ("sempre que tratado paternalmente, [o escravo] foi indivíduo mais ou menos conformado com seu status"). ${ }^{4}$

Essa visão de uma relação até certo ponto harmônica entre senhores e escravos, no Brasil, foi incorporada por alguns historiadores norte-americanos, que procuraram contrastar o escravismo dos Estados Unidos, visto como mais opressivo e segregador, com o brasileiro (e latino-americano), comparativamente mais favorável aos cativos e aos libertos. Num livro influente, publicado em 1947, Frank Tannenbaum, citando Freyre, ressaltou o fato de que "in Brazil the Negro, and especially the mulatto, had an access to the culture and a role in social life unknown in the United States". Um sinal da diferença entre os dois casos seriam atitudes sociais divergentes com respeito à escravidão, como na questão da miscigenação: "in Brazil it was accepted as a matter of course and has come to be, to a certain extent, a point of pride". Em contraste, "in the British and French West Indies and in the United States, it was frown upon, forbidden by law, denied, and condemned (...)". (Tannembaum, 1947:4,121)..$^{5}$

A noção de uma escravidão amena enfrentou, por outro lado, forte oposição por parte de vários autores, como os ligados à chamada escola paulista de Sociologia. Sob a liderança de Florestan Fernandes, esse grupo produziu, nas décadas de cinqüenta e sessenta, trabalhos influentes sobre o escravismo brasileiro. ${ }^{6}$ Nessa perspectiva crítica, a tese da benignidade foi às vezes vista como mera tática de racionalização ou defesa do regime escravista por parte dos interessados em sua sobrevivência. Para Octávio Ianni, por exemplo, a interpretação de

\footnotetext{
${ }^{4}$ Freyre (1996[1936]:523-525); Freyre (1981[1933]:220).

${ }^{5}$ Sobre a tese de Tannenbaum e extensões e debates posteriores, cf. Elkins (1976).

${ }^{6}$ e.g.: Bastide e Fernandes (1959); Cardoso e Ianni (1960); Cardoso (1962); Ianni (1962); Fernandes (1965).
} 
Freyre - elaborada "na perspectiva do senhor da casa-grande, do branco da casta dominante" - refletiria apenas "a ideologia dos senhores da época dos escravos e a ideologia dos senhores da época de Gilberto Freyre”. Da mesma forma, as opiniões dos viajantes e cronistas estrangeiros expressariam principalmente "ilusões, ou auto-representações, que os senhores da casa-grande e do sobrado lhes transmitiam de forma deliberada, ao acaso dos repastos”. (Ianni, 1988:107,113).

A difusão da tese da benignidade teria decorrido, também, dos esforços de propaganda antiabolicionista do governo imperial. Os viajantes teriam agido, segundo a historiadora Emília Viotti da Costa, como "verdadeiros agentes do Governo brasileiro", divulgando no exterior "uma visão falsificada da realidade brasileira" (Costa, 1966:281). Na mesma linha, outro historiador, Jacob Gorender, concluiu: "Assim, com incentivo oficial, forjou-se o mito da benignidade da escravidão no Brasil (...).” (Gorender, 1980:350). Para o brasilianista Robert Conrad, a pregação escravagista do governo brasileiro teria até mesmo influenciado, um século mais tarde, o debate sobre as características comparadas da escravidão no Brasil e nos Estados Unidos, induzindo ao erro historiadores norte-americanos. ${ }^{7}$

\section{A PERSPECTIVA DA ANÁLISE ECONÔMICA: COERÇÃO E MAXIMIZAÇÃO DA PRODUÇÃO ${ }^{8}$}

$\mathrm{Na}$ escravidão, tanto quanto no trabalho livre, o empresário pode em princípio usar uma combinação de incentivos positivos e negativos para obter da mão-de-obra o desempenho desejado, visando a maximização do lucro. Como observou Findlay (1975), do ponto de vista analítico, o problema da escolha dessa combinação é essencialmente o mesmo, nos dois casos; a grande diferença reside na natureza da coerção que pode ser aplicada. ${ }^{9}$

\footnotetext{
7 “The [Brazilian] pro-slavery propaganda, though perhaps intended mainly for foreigners, influenced the thinking of many Brazilians (...). [In the First Republic (1889-1930)] certain historians, aided by a few foreigners, were elevating the theory of a milder Brazilian slavery to the level of historical science.(...) Such writers contributed greatly to Gilberto Freyre's theories (...), and it was Freyre's impressive scholarly works that inspired Frank Tannenbaum's brief comparative study of slavery and race relations in the Americas, which in turn stimulated a virtual school of American scholarship eager to prove, or at least to believe, that slavery in the United States was particularly inhumane. One wonders how many historians who welcomed these ideas understood that they were based in part at least upon the inventions of former defenders and apologists of Brazilian slavery" (Conrad, 1994:xxiii).

${ }^{8}$ Para análises do uso de coerção no controle da mão-de-obra escrava, sob o ponto de vista da teoria econômica, v., por exemplo: Findlay (1975), Barzel (1977), Fenoaltea (1984), Kahn (1992), Fogel e Engerman (1974:v.2, 155ss.), Chwe (1990). Alguns pontos desta seção foram desenvolvidos em Versiani (1994).

9 "The only difference between the two systems would be that the 'supervisor' in the slave system is more likely to use a whip to correct negligence, while in the free system he is more likely to use threats of dismissal or slower promotion up the job ladder." (Findlay, 1975:927).
} 
A preferência por métodos coercitivos, na escravidão, é explicada de mais de uma forma na literatura. Fogel e Engerman (1974), em sua análise do escravismo do sul dos Estados Unidos, ressaltaram as economias de escala propiciadas por uma organização do trabalho que só seria viável sob o regime escravista. O trabalho nas grandes plantations seria mais eficiente do que na agricultura familiar, especialmente no cultivo do algodão, em decorrência da forma de produção: os trabalhadores, dispostos em turmas, sob supervisão estreita, operavam num ritmo intenso e disciplinado, com especialização de tarefas, como numa linha de montagem. A mão-de-obra livre não se submeteria a condições de trabalho tão rigorosas - a não ser por um salário tão alto que tornaria o empreendimento não-lucrativo. Já o escravo poderia ser coagido, pela força, ao desempenho desejado. ${ }^{10}$

$\mathrm{Na}$ abordagem mais geral de Barzel (1977), esse último é o ponto central: independentemente de economias de escala, o escravo, não sendo dono de seu tempo, pode ser forçado a trabalhar mais - um maior número de horas diárias, por exemplo - do que o trabalhador livre estaria disposto a fazer à taxa usual de salário. O poder discricionário que o proprietário legalmente detém sobre seus escravos faz com que a oferta de trabalho seja determinada por aquele, e não pelos próprios trabalhadores. ${ }^{11}$ Nessas circunstâncias, mesmo supondo que a produção horária de um assalariado e de um escravo seja a mesma, o produto diário do escravo será maior que o do trabalhador livre. Dado um mesmo custo monetário por dia, nos dois casos (incluindo, no caso dos cativos, o custo da coerção), a opção do empresário seria pelo trabalho escravo. A coerção tem, assim, um significado econômico objetivo: é um instrumento de maximização da produção.

No entanto, é evidente que o uso de métodos coercitivos como meio para maximizar a produção será mais eficaz em certas atividades do que em outras. A assimetria de informação entre o senhor e o escravo - que dá origem ao clássico problema do agente - pode variar consideravelmente. O senhor determina as atividades que o escravo exercerá, visando determinado objetivo de produção, mas não tem toda informação sobre como essas atividades são exercidas, ou sobre o resultado delas. Só o próprio agente direto dessas ações, o escravo, sabe se todo o esforço possível está sendo despendido e, portanto, se o nível de produção é o máximo que poderia ser atingido; nesse sentido, o escravo tem uma vantagem informacional sobre o senhor. ${ }^{12}$ Para conhecer o desempenho da mão-de-

\footnotetext{
10 "From the master's viewpoint, the advantage of force (...) was that it produced desired behavior, in certain realms of activity, at a lower cost than it could have been achieved through financial inducements." (Fogel e Engerman, 1974:v. 2,237).

11 "In a nonslave economy, an individual determines the amount of labor he is willing to supply simultaneously with his consumption decisions. (...) In a slave economy, however, both the amount of labor to be extracted from a slave and his consumption or 'feeding' are determined by the slave owner. Thus, the labor market for slaves differs from that for freemen by the decision-making unit through which options are exercised.” (Barzel, 1977:87).

${ }^{12}$ Num sentido estrito, como observou Charles Kahn, "this information advantage is [the slave's] sole possession". (Kahn, 1992:565 n.7).
} 
obra escrava e avaliar sua adequação, o senhor terá de exercer ações de monitoramento e controle. Contudo, a eficácia e o custo dessas ações dependerão crucialmente do tipo de atividade sendo desenvolvida.

Quando se trata de tarefas simples e repetitivas, exercidas simultaneamente por um número relativamente grande de escravos, esse controle é facilitado, e a coerção ganha eficácia. Em contraste, em tarefas mais complexas e de pequena escala, como a do artesão, o uso da força como instrumento de obtenção de determinado comportamento será claramente pouco indicado. Como notou Findlay (1975:924), essa distinção entre modelos de escravidão, um baseado na coerção (stick slavery) e outro em incentivos (carrot slavery), está presente na literatura pelo menos desde 1928, em artigo do historiador Zimmern sobre a escravidão greco-romana.

É útil, nesse contexto, a caracterização, devida a Fenoaltea (1984), de dois tipos polares de tarefas na atividade produtiva: tarefas "intensivas-em-esforço" e "intensivas-em-habilidade". Nas primeiras, em que predomina a força física, pode-se em geral observar diretamente o resultado do trabalho em termos quantitativos (a área roçada, o número de covas preparadas para o plantio, a quantidade de canas cortadas ou de café colhido etc.). A assimetria de informação é minimizada. Isso possibilita que um mesmo supervisor monitore o trabalho de um grupo de trabalhadores, facilitando a organização da atividade de produção em turmas, no chamado sistema de gang work, típico das grandes unidades agrícolas escravistas. A coerção - um feitor com o chicote - será, nesse caso, instrumento eficaz para consecução do objetivo de maximização da produção. ${ }^{13}$

Por outro lado, em atividades "intensivas-em-habilidade", a qualidade de execução é de importância central. Comumente escravos exerciam tarefas dessa natureza no artesanato, na criação de gado, na mineração de ouro, no trabalho doméstico ou urbano etc. Também na antigüidade, grande parte da mão-de-obra escrava estava engajada em ocupações desse tipo: artesãos, artistas, oficiais da marinha romana, policiais de Atenas e assim por diante (Findlay, 1975:924). Nesses casos a assimetria de informação aumenta, e a avaliação direta dos resultados da produção é dificultada pela própria natureza das atividades (como determinar se a busca de pepitas de ouro entre o cascalho do aluvião foi suficientemente bem feita? ou se o carpinteiro produziu uma peça suficientemente sólida?) e ainda pelo fato de que são tarefas em geral executadas individualmente, e não por grupos de escravos. Como observou Fenoaltea (1984:640), no limite, seria necessário um supervisor para monitorar cada escravo com funções desse tipo. O monitoramento direto pode mesmo ser inteiramente inviável, na medida em que a

\footnotetext{
${ }^{13}$ O papel da coerção, do ponto de vista do senhor de escravos, foi expresso de forma cristalina, em 1839, pelo cafeicultor C.A.Taunay, em seu Manual do Agricultor Brasileiro:

"[S]empre que os homens são aplicados a um trabalho superior ao prêmio que dele recebem, (...) é preciso sujeitá-los a uma rigorosa disciplina, e mostrar-lhes o castigo inevitável. Sem este meio (...) um preto não se sujeitaria nunca à regularidade de trabalhos que a cultura da terra requer. (...) [S]ó a coação e o medo o poderão obrigar a cumprir sua tarefa." (apud Marquese, 2004:272-74).
} 
qualidade da execução só possa ser avaliada depois de decorrido algum tempo (quando, por exemplo, à qualidade se associar a durabilidade, como num trabalho de carpintaria).

Quanto maior a dificuldade de monitoramento, menor a eficácia da coerção e maior a vantagem relativa do oferecimento de incentivos positivos, com o propósito de angariar a cooperação do escravo em lugar de coagi-lo ao desempenho desejado. Um tratamento melhor; a permissão de que o escravo tivesse uma atividade remunerada em dias de folga; o compartilhamento da receita auferida, no caso dos escravos "de ganho"; a promessa de alforria - tudo isso são exemplos de incentivos positivos, de que há abundante evidência histórica. A escravidão não-coercitiva será ainda preferível à mão-de-obra assalariada, desde que a produtividade líquida do trabalho escravo seja superior à do trabalho livre..$^{14}$

A diferença entre o nível de vida superior dos escravos que desempenhassem tarefas de habilidade, e o nível de subsistência (que era o que tocava aos escravos da stick slavery) pode ser interpretada como o rendimento decorrente da vantagem informacional detida pelos primeiros, dada a dificuldade do monitoramento de suas atividades (cf. Kahn, 1992:556). Há aqui uma analogia evidente com o pagamento de salários de eficiência, em mercados de trabalho duais. ${ }^{15}$

Pode-se admitir, portanto, que o custo de monitoramento fosse menor nas grandes unidades escravistas. Em primeiro lugar, pela economia de escala na supervisão e controle dos escravos: grandes plantéis estavam em geral ligados à lavoura extensiva, onde os escravos eram tipicamente organizados em turmas. ${ }^{16}$ Nesse caso, sendo o monitoramento praticado de forma coletiva (digamos, um feitor para vinte ou trinta escravos), reduzia-se correspondentemente seu custo per capita. Além disso, pela natureza da atividade exercida: as tarefas típicas dessas turmas de escravos, na grande lavoura, eram em geral simples e repetitivas ("intensivas-em-esforço"), o que facilitava o monitoramento coletivo.

De outra parte, as referências a pequenos plantéis de escravos, na literatura, sugerem que as tarefas exercidas pelos cativos, de natureza variada, eram, regra geral, “intensivas-em-habilidade". Esse era certamente o caso na esfera doméstica (cozinheiras, mucamas), ou no trabalho escravo aplicado à atividade produtiva em pequena escala (artesanato, comércio, transporte urbano ou marítimo etc). ${ }^{17}$ Tarefas de difícil monitoramento, como se viu. $\mathrm{Na}$ área rural, as propriedades

\footnotetext{
14 "Slavery only endured in areas and occupations where their productivity net of policing costs still exceeded that of freemen (...)." (Barzel, 1977:109).

${ }^{15}$ Comparar: "[I]f shirking is a problem in some sector or firm where monitoring of work effort is costly (...), then we might expect to observe the payment of efficiency wages in this sector or firm but not in others, (...) where perhaps monitoring is not such a problem." (Hillier, 1997:131).

${ }^{16}$ Descrições relativas a plantações de algodão do sul dos Estados Unidos organizadas pelo gang system, sugerem que o tamanho médio dessas turmas era de cerca de trinta escravos (Phillips, 1969[1918]:240).

${ }^{17}$ Para os setores de atividade típicos de proprietários de pequenos plantéis de escravos, ver as referências citadas na $5^{\underline{a}}$ seção, abaixo.
} 
que utilizavam poucos escravos tinham, no mais das vezes, produção diversifica$\mathrm{da}$, o que acarretava igualmente diversificação de tarefas por parte dos trabalhadores. ${ }^{18}$ Isso, aliado ao pouco vulto da produção, fazia com que os cativos muitas vezes trabalhassem individualmente ou em pequenos grupos, não raro longe das vistas do dono; e até mesmo, na ausência deste, administrando sozinhos a propriedade. Os relatos de viagem de Saint-Hilaire fornecem numerosos exemplos dessas situações - nas quais é evidente que o monitoramento seria problemático e a punição física, uma forma ineficiente, ou mesmo inviável, de controle da mão-de-obra. ${ }^{19}$

É significativo que, mesmo em atividades onde prevaleceriam tarefas "intensivas-em-esforço" (com menor custo de monitoramento), como nos engenhos de cana-de-açúcar, há indicações de que a coerção fosse menos comum, no caso de pequenos plantéis. Nesse caso, não seria possível organizar os trabalhadores em turmas, na forma característica de plantation, com feitores ditando o ritmo da atividade; isso exigiria um número mínimo de escravos, algo como vinte ou trinta (ver as notas nos 17 e 32 ). Com poucos escravos, nem caberia utilizar feitores; um controle mais direto, pelo próprio dono (que muitas vezes trabalharia lado a lado com seus poucos cativos), faria menos presentes o chicote e o tronco. ${ }^{20}$ Pode-se recorrer, outra vez, ao testemunho idôneo de Saint-Hilaire: ele visitou inúmeros engenhos, em todas as províncias que percorreu; mas apenas num caso, o da região de Campos, no Rio de Janeiro, suas minuciosas descrições mencionam - com enérgica reprovação - o uso de métodos coercitivos, e mesmo cruéis, no trato dos cativos. E foi apenas nessa região que o naturalista pôde ver unidades de produção de açúcar em grande escala, empregando numerosa escravaria (Versiani, 2000).

De uma maneira geral, pode-se supor uma relação inversa entre o tamanho dos plantéis e o custo do monitoramento; assim sendo, seria de esperar que a coerção fosse mais eficaz do ponto de vista dos senhores - e, portanto, mais freqüente -, nas propriedades com grande número de escravos, e menos habitual no caso de plantéis pequenos. A evidência histórica parece corroborar essa suposição. No caso dos Estados Unidos, depoimentos de ex-escravos mostram que castigos físicos eram mais comuns em plantações com maior número de escravos, especialmente naquelas com mais de cem cativos (Crawford, 1992:540-41). No Brasil, há depoimentos no mesmo sentido: segundo Rugendas (1975[1835]:

\footnotetext{
${ }^{18}$ Por exemplo: Saint-Hilaire (1975[1830]:172) observou, em fazendas de Minas Gerais, o uso de trabalho escravo no cultivo simultâneo de algodão, milho e feijão - que não exigem tratos constantes ao longo do ano.

${ }^{19}$ Saint-Hilaire viu escravos trabalhando longe dos senhores, ou cuidando de fazendas de proprietários ausentes ou absenteístas, em diversas situações e regiões (Rio de Janeiro, Minas, São Paulo, Paraná, Rio Grande do Sul). Ver: Versiani (2000).

${ }^{20} \mathrm{Em} 1829,43 \%$ dos produtores de açúcar escravistas tinham menos de 20 escravos, em São Paulo; muitos deles complementariam a mão-de-obra cativa com seu próprio trabalho, ou de sua família. Em 1804, aquela proporção subia a 70\%. Luna e Klein (2003:126).
} 
266-67), por exemplo: “Os escravos (...) são mais bem tratados nas pequenas fazendas do que nas grandes (...).”. E o fato de que o trato fosse mais rigoroso nas fazendas do que nas cidades, como refere Costa (1966:284-85), aponta na mesma direção: nos grandes plantéis das fazendas predominavam atividades "intensivas-em-esforço", enquanto nas cidades, onde o número de escravos por senhor era muito inferior, eram mais comuns as "intensivas-em-habilidade". ${ }^{21}$

\section{GILBERTO FREYRE E A ESCRAVIDÃO “BRANDA”}

A análise acima sugere uma releitura das idéias de Gilberto Freyre sobre a natureza branda da escravidão brasileira, esboçada a seguir.

Cabe observar, de início, que um exame atento das obras desse autor deixará claro que ele se refere a formas bem específicas de escravidão quando fala num tratamento ameno dos escravos no Brasil. Ou alude à escravidão doméstica objeto talvez preponderante de sua análise - , ou, quando se reporta à mão-deobra escrava engajada na produção de mercadorias, restringe seus argumentos a um tipo bem determinado de unidade produtiva.

O fato de que Gilberto Freyre deu atenção primordial à escravidão doméstica tem sido notado na literatura. Como assinalou Darcy Ribeiro:

"Buscando com muito zelo, ao longo das centenas de páginas de Casa Grande e Senzala, o leitor colherá aqui e ali alguma referência ao negro multitudinário, comum, ordinário; ao negro que com as vergonhas cobertas por uma tanga foi o principal contingente trabalhador do Brasil. Muito poucas, na verdade. Pouquíssimas são suas anotações sobre este negro-massa, trabalhador do eito." (Ribeiro, 1986:157).

Em várias passagens, Freyre faz distinções explícitas entre as formas de tratamento de escravos domésticos e de outros escravos. Mencionando, por exemplo, o fato de que diversas cartas-régias, no século XVII e início do XVIII, "indicavam que muitos senhores não davam então aos escravos o necessário descanso nem tempo de trabalharem para si", Freyre comenta: "mas é evidente que se referiam antes à escravaria grossa que aos escravos do serviço doméstico". Estes últimos eram também "beneficiados por uma assistência moral e religiosa que muitas vezes faltava aos do eito". Haveria de fato uma hierarquia ou gradação entre escravos, ocupando os domésticos a posição superior: "nessa hierarquia, a parte aristocrática eram os escravos do serviço doméstico", que eram muitas vezes tratados "quase como pessoa de família". Ficavam esses escravos, admitidos na intimidade das casas dos senhores, como uma "espécie de parentes pobres nas famílias européias" (Freyre 1981[1933]: 475-76, 450, 476, 352).

Era a esses escravos "quase-parentes" que o senhor reservava o melhor tra-

${ }^{21}$ A partir de um modelo formal baseado na teoria do agente, Kahn (1992) chegou à mesma conclusão: deveria haver menor custo de monitoramento, e maior incidência de coerção, em grandes plantéis. 
tamento. Em certas situações, diz Freyre, o senhor de escravos mostrava sentimentos de piedade com relação aos seus escravos. Mas "esses sentimentos, o senhor patriarcal do Brasil limitava-se a dispensá-los àqueles escravos ou servos que considerava uma espécie de pessoas da casa: mães-pretas, mucamas, malungos. (...) Pelos outros, sua indiferença era tal, que confundia-se às vezes com crueldade." (Freyre, 1996[1936]:494).

Mas Gilberto Freyre não deixou de referir-se, quando falou de formas mais condescendentes de trato de escravos, à "escravaria grossa" do eito, ao "negromassa" de Darcy Ribeiro. Ao contrário, menções explícitas a esse tipo de escravos são freqüentes em seus livros, nesse contexto. O que se nota, no entanto, é que ele se reporta, nesse caso, aos escravos de um gênero bem definido de propriedade agrícola. Essencialmente, ele associa o bom trato dos escravos à ausência de uma preocupação dominante com a busca do lucro, por parte dos seus proprietários. Enquanto alguns senhores "consideravam seus escravos como máquinas", outros, ao contrário, e "talvez o maior número (...) consideravam seus negros pessoas". Esses - "que [não] faziam da acumulação de riquezas seu fim principal na vida" - eram "os brasileiros já antigos no Brasil e na posse de terras e de negros". Ou seja: os escravos podiam esperar uma situação favorável naquelas velhas propriedades, onde os escravos "passavam de pai a filhos" (Freyre, 1996[1936]:525; Freyre, 1937:137).

Freyre contrasta essas velhas propriedades com "fazendas ou engenhos de proprietários que apenas começavam a fazer fortuna: homens ansiosos de lucros rápidos. Fazendas ou engenhos onde se explorava o escravo do modo mais rude: espremendo-se o coitado até o último pingo de rendimento." Da mesma forma, "o senhor pobre, quando ambicioso ou sôfrego de ascensão social ou econômica procurava extrair o máximo dos poucos escravos a seu serviço". (Freyre, 1996[1936]: 177, 287).

Há uma insistência nos elementos de estabilidade e continuidade de relações sociais, na caracterização do meio ambiente onde, para Freyre, teriam prosperado as atitudes benignas dos senhores em relação aos escravos. "Era demorando numa casa, numa fazenda ou numa estância, afeiçoando-se a uma família ou a um senhor, que o escravo se fazia gente da casa, pessoa da família." E demorando em velhas propriedades, que passavam solidamente de geração em geração, sem que seus proprietários desejassem ou buscassem grandes mudanças ou enriquecimento rápido (Freyre, 1996[1936]:526).

Nota-se uma correspondência estreita entre essa caracterização do senhor de escravos benevolente e a descrição de um tipo análogo, no livro de Stampp sobre a escravidão no Sul dos Estados Unidos:

"After lands and slaves had remained in the hands of a single family for several generations, planters sometimes developed a patriarchal attitude toward their 'people' and took pride in treating them indulgently. Such masters had lost the competitive spirit and the urge to increase their worldly possessions which had characterized their ancestors. To 
live gracefully in their declining estates, to smile tolerantly at the listless labor of their field-hands, and to be surrounded by a horde of pampered domestics were all parts of their code.” (Stampp, 1956:76).

A grande diferença é que, enquanto Stampp ressalta que esses casos constituíam uma rara exceção no sul dos Estados Unidos, Freyre sustenta que no Brasil tendiam a ser a regra, sob o domínio do patriarcalismo, em particular no Nordeste açucareiro. Nisso ele se apóia muito no livro de Koster, de 1816 (a obra mais citada em Casa Grande e Senzala e Sobrados e Mucambos). Para Koster, "Esse espírito de avareza que faz trabalhar um homem como um animal bruto até que se esgote para qualquer serviço, (...) como se fosse feit[o] de madeira ou ferro, é raramente visto no país". Predominaria a atitude daquele que "herdou sua propriedade, e não [tem] urgência em obter largos proveitos. (...) Seus hábitos de tranqüilidade e de indolência o levam a ser doce mas indiferente, e não toma o cuidado com a própria manutenção de sua escravaria que um europeu teria." (Koster, 1942[1816]: 479).

No que se refere ao Nordeste açucareiro dos séculos XVIII e XIX, a idéia de que prevalecia uma postura de pouca preocupação com a maximização do lucro entre os senhores de engenho, encontra apoio num argumento de Celso Furtado (1976[1959]: cap.12). A economia açucareira da região, após o auge do século XVII, passou por um processo secular de semi-estagnação, com baixos preços e lucratividade. Segundo Furtado, dado que os custos do engenho eram quase todos fixos (associados à formação do canavial, montagem do engenho e compra de escravos), mesmo com preços baixos continuava valendo a pena produzir, desde que a receita de vendas cobrisse os (reduzidos) custos variáveis de produção, pois ainda assim haveria um excedente a ser apropriado pelo senhor de engenho. A decadência secular na lucratividade do açúcar não induzia o abandono dessa atividade, mantendo-se inalterada a estrutura produtiva.

Mas ocorriam mudanças na atitude e no estilo de vida do dono de engenho, que se tornava menos um empresário e mais um rentista, vivendo dos rendimentos do capital acumulado no passado. A baixa lucratividade fazia com que houvesse pouco ou nenhum incentivo para investir no aumento de produção; com isso, ganhavam espaço os gastos de consumo. Por exemplo: sendo desnecessário usar todos os escravos na produção, pela insuficiência de mercado comprador, aumentava sua utilização na unidade doméstica como amas, cozinheiras, artífices variados, moleques de recados, mucamas etc. $\mathrm{O}$ aumento de produção de açúcar, a partir das últimas décadas do século XVIII e ao longo de boa parte do século XIX, trouxe de volta certa medida de prosperidade à região açucareira nordestina, mas certamente não eliminou do quadro social da região a figura do patriarca tutelar — tão presente na ficção nordestina do século XX -, pouco identificável com a descrição clássica do empresário capitalista.

Em suma: os escravos supostamente bem-tratados, na visão de Gilberto Freyre, ou eram escravos domésticos ou pertenciam a proprietários rurais afidalgados, para os quais a maximização da produção não era um objetivo primordial. 
Em ambos os casos, seria de esperar, como vimos, uma baixa incidência de métodos coercitivos para com os cativos, o que daria suporte ao argumento de Freyre.

No entanto, permanece em aberto a questão da generalidade desse argumento. Escravos domésticos eram uma minoria, e a ocorrência de senhores de engenho rentistas, sem preocupação com o lucro, foi um fenômeno localizado no espaço e no tempo. Haveria elementos para estender a outras regiões ou épocas a idéia de um tratamento relativamente brando dos escravos? A próxima seção aborda esse tema.

\section{ESCRAVIDÃO COERCITIVA E NÃO-COERCITIVA: ALGUMA EVIDÊNCIA}

É comum a suposição de que o escravo da grande lavoura fosse o escravo típico, no Brasil. Essa é, certamente, a visão leiga usual do regime escravista: turmas de cativos, num engenho ou cafezal, trabalhando sob a vigilância e o chicote de um feitor. Também na literatura erudita esse é um pressuposto freqüentemente adotado, como fica claro, por exemplo, no trecho de Darcy Ribeiro acima mencionado, onde o "negro multitudinário", o "negro-massa" é o trabalhador do eito. Deriva dessa crença, sem dúvida, a idéia de que a coerção e a violência fossem um dado universal do regime escravista, entre nós. Como expresso pelo próprio Darcy Ribeiro que, analisando em outra obra a influência africana na cultura brasileira, afirmou que o escravo foi submetido, no Brasil, a um regime de "coerção permanente, exercida através dos castigos mais atrozes”. (Ribeiro, 1995:118). Como visto acima, uma coerção generalizada só fará sentido na medida em que a produção em grande escala seja a forma típica de utilização do trabalho escravo.

No entanto, vários trabalhos nas duas últimas décadas têm evidenciado a importância, no escravismo brasileiro, da utilização de mão-de-obra escrava em outros tipos de atividade que não a grande lavoura, caracterizando uma organização do trabalho escravo radicalmente diferente da associada ao sistema de plantation. Estudos referentes a diversas regiões e períodos têm convergido em revelar três aspectos principais. Primeiro, que a posse de escravos era muito difundida entre a população livre, de tal forma que o senhor de escravos típico, modal, tinha freqüentemente não mais que um ou dois cativos. Segundo, que mesmo em atividades produtivas voltadas à exportação ou associadas a estas, foi comum a ocorrência de unidades relativamente pequenas, com um número reduzido de escravos. O número médio de escravos por senhor era assim, em muitas situações, relativamente baixo.

Terceiro - e é o ponto que nos interessa aqui - a maioria dos escravos, em várias regiões e períodos, pertencia a senhores que tinham poucos cativos. $\mathrm{Ou}$ seja, o escravo típico, nesses casos, não fazia parte de um grande plantel, mas sim de um pequeno conjunto de escravos.

Um dos primeiros trabalhos nessa linha foi o de Francisco Luna (1981), com base em arrolamentos populacionais de cinco localidades na área de exploração 
aurífera de Minas Gerais, em diferentes fases do ciclo minerador $(1718,1723$, $1738,1771,1790$ e 1804). Dos cerca de 14.500 escravos arrolados, mais de três quartos pertenciam a plantéis de até 20 escravos $(76 \%$, variando essa proporção de $70 \%$ a $87 \%$, nos sete arrolamentos examinados) e mais da metade a plantéis menores, de não mais que 10 cativos (57\%, variando de $48 \%$ a $71 \%$ ). A média de escravos por senhor variou no intervalo de 3,7 a 6,5 , e a moda de 1 a $2 .{ }^{22} \mathrm{O}$ mesmo autor, examinando arrolamentos para quatro localidades mineiras relativos a um mesmo ano (1718), encontrou praticamente a mesma estrutura de posse de escravos: $73 \%$ dos cativos pertenciam a plantéis de até vinte indivíduos (com variação entre $67 \%$ e $85 \%$ ), e $46 \%$ a plantéis de no máximo dez escravos (com variação entre $39 \%$ e $66 \%$ ). A média de escravos por proprietário variou de 6,2 a 6,9 , e a moda, de 1 a $2 .{ }^{23}$

A grande difusão da propriedade escrava em Minas é evidenciada pela alta proporção de domicílios com escravos, no censo de 1804, analisado por Iraci Costa. Essa porcentagem era, por exemplo, de 41\%, em Vila Rica, e 45\%, em Santa Luzia (Nero da Costa, 1981:251,329).

Quanto à Minas Gerais do século XIX, as pesquisas de Clotilde Paiva (1996), baseadas em listas nominativas de toda a província, para 1831-32, fornecem um quadro mais detalhado da distribuição da população escrava, com características similares às descritas por Francisco Luna e Iraci Costa. Dois terços dos cativos (66\%) faziam parte de plantéis com até vinte escravos, e 44\% pertenciam a plantéis com até dez escravos. Metade dos senhores tinha não mais do que três cativos; e cerca de um terço dos domicílios (32\%) tinha escravos. ${ }^{24}$ Aparentemente o padrão de posse de escravos não variou muito, em Minas, ao longo dos séculos XVIII e XIX: é o que sugerem também os dados de Bergad, originários de ampla pesquisa em inventários de três regiões da província, abrangendo todo o período de $1720-1888.25$

Para a Bahia, Stuart Schwartz (1982) analisou uma listagem de cerca de 34 mil escravos do Recôncavo, em 1816-17, o que corresponderia a cerca da metade

\footnotetext{
${ }^{22}$ Dados básicos em Luna (1981:68, 87, 93, 98, 107, 113, 126). Os arrolamentos são de Pitangui (1718 e 1723), Serro (1738), Congonhas do Sabará (1771 e 1790), S. Caetano (1804) e Vila Rica (1804).

${ }^{23}$ Dados básicos em Luna (1983: Tabelas 1 a 4). Os arrolamentos são de Vila Rica, Vila do Carmo (hoje Mariana), São João del-Rei e Pitangui. A amostra é de 14.665 escravos.

${ }^{24}$ Dados básicos em Paiva (1996:138; Apêndices 1 e 3). As listas nominativas referem-se a 397.282 habitantes (correspondendo a cerca de $55 \%$ da população estimada da província), dos quais 134.108 escravos.

${ }^{25}$ Bergad (1999) levantou informações para mais de 110 mil escravos, em inventários de Diamantina, Ouro Preto, Mariana, São João del-Rei e Tiradentes. A proporção de escravos em plantéis de até vinte cativos oscila em torno de 50\% em todo o período (Bergad, 1999:Table 5.5). Pode-se presumir que as informações de inventários subestimem os plantéis muito pequenos, na medida em que muitos desses pertenceriam a indivíduos de poucas posses, cujos bens não seriam objeto de inventário; isso poderia explicar a menor proporção de escravos em pequenos plantéis, no estudo de Bergad, em comparação com os números de Paiva.
} 
dos cativos dessa região, e perto de um quarto do total da província. Embora fosse uma área de grande produção de açúcar, os escravos dos 165 engenhos eram pouco menos de um terço do número total de cativos. Assim, embora o número médio de escravos por engenho fosse relativamente alto $(65,5)$, a média global de cativos por senhor era de apenas 7,2 , próxima do valor encontrado na região das minas. Mais da metade dos escravos da amostra (53\%) pertenciam a senhores com menos de vinte escravos; e um terço $(36 \%)$ a senhores com menos de dez escravos. ${ }^{26}$

A análise das listas nominativas da província de São Paulo, em fins do século XVIII e primeiras décadas do século XIX (abrangendo, então, o atual estado do Paraná), resenhada por Luna e Klein (2003), mostra resultados parecidos. Nos censos de 1777, 1804 e 1829, cerca de uma quarta parte dos domicílios tinha escravos; e a média de cativos por senhor variou de 5,5 a 7,0, entre o primeiro e o último desses anos. A grande maioria dos proprietários tinha não mais que cinco escravos. Em 1804, cerca de três quartos dos escravos (73\%) pertencia a plantéis de até vinte cativos, e $50 \%$ a plantéis de até dez. Em 1829, essas proporções eram menores $(61 \%$ e $40 \%$ respectivamente - números muito próximos dos de $\mathrm{Mi}$ nas Gerais na mesma época), mas a grande maioria dos escravos ainda pertencia a unidades que não se caracterizavam como da grande lavoura. Mesmo no caso de escravos pertencentes a cafeicultores, a maioria (54\%) fazia parte de plantéis de até vinte cativos, uma indicação de que produtores de pequeno porte tinham peso relevante nessa atividade no período. ${ }^{27}$

A importância de pequenos e médios produtores na cafeicultura paulista foi evidenciada também na fase posterior de grande expansão dessa lavoura. Em Taubaté, por exemplo, grande centro cafeicultor do Vale do Paraíba, mais da metade do café produzido, em 1868, provinha de pequenos e médios cultivadores. Isso se refletia na estrutura de posse de escravos: os dados da matrícula de 1872 mostram que $55 \%$ dos cativos de Taubaté pertenciam a plantéis pequenos, de menos de vinte escravos; e $36 \%$ faziam parte de plantéis de não mais que nove escravos (Marcondes, 1998:Tabelas 1 e 2). Outros dados para cinco localidades cafeeiras do Vale do Paraíba paulista, em 1872-74, mostram um quadro heterogêneo: em quatro delas, as médias de escravos por cafeicultor eram inferiores ou pouco superiores a vinte, mostrando o peso de pequenos e médios produtores; em um caso (Bananal) aquela media era alta (78), sugerindo prevalência da grande propriedade. (Marcondes, 2002).

Também no caso de Pernambuco, pesquisas recentes mostraram que uma parcela substancial dos escravos da província, no século XIX, não estava na re-

\footnotetext{
${ }^{26}$ Schwartz (1982:Tabelas 1 a 8); ver também Schwartz (1985: cap. 16). Informações adicionais sobre a utilização de mão-de-obra escrava em pequenas propriedades, no Recôncavo, encontram-se em Barickman (1998).

${ }^{27}$ Luna e Klein (2003:Tabelas 5.2 a 5.6). Os dados das listas nominativas de São Paulo têm dado origem, nas três últimas décadas, a um conjunto importante de trabalhos sobre a estrutura de posse de escravos na província por pesquisadores da USP. V., por exemplo, além dos textos citados acima: Luna e I.N.Costa (1983); I.N.Costa e Nozoe (1989); Luna (1988 e 1998); Motta (1999).
} 
gião açucareira (a Zona da Mata), mas no Agreste e no Sertão, onde predominavam pequenos plantéis escravistas (Versiani e Vergolino, 2002). ${ }^{28}$ Dados de inventários - que, como se mencionou, tendem a subavaliar os pequenos plantéis — indicam, no período 1800-1830, que enquanto não mais que $3 \%$ dos escravos da Zona da Mata pertenciam a plantéis de até vinte cativos, essa proporção subia a $69 \%$, no Agreste, e $72 \%$, no Sertão.

Ao longo do século, esses percentuais de cativos em pequenos plantéis tenderam a aumentar, muito especialmente no caso da Mata açucareira, onde a proporção de escravos pertencentes a plantéis de vinte ou menos cativos atingiu $40 \%$ entre 1850 e 1888 , provavelmente em decorrência de um aumento do número de lavradores de cana, fornecedores dos engenhos. Aliás, uma redução correspondente do número de escravos por engenho foi observada em Sergipe, entre a primeira e a segunda metades do século XIX (Passos Subrinho, 2000:96 ss.). No total dos inventários de Pernambuco, em todo o período 1800-1888, o número médio de escravos por inventários contendo escravos foi de 8,6, caindo de 12,0, na primeira metade do século, para $6,4 \mathrm{em} 1850-88 .{ }^{29}$ Os dados de inventários sugerem que a maior parte do número total de escravos dessa província açucareira pertencesse, no período após 1850 , a plantéis pequenos, de até vinte cativos. ${ }^{30}$

Em suma, os achados acima referidos apontam para uma escravidão muito mais complexa e variada do que usualmente se supunha. Usava-se o trabalho escravo em diversas outras formas de atividade produtiva, além da grande lavoura. E mesmo os produtos típicos da grande lavoura eram também, freqüentemente, produzidos em pequenas ou médias unidades, com poucos escravos. Embora seja necessário maior esforço de pesquisa até que se tenha um quadro mais nítido do padrão de propriedade de escravos no País como um todo, a evidência já disponível mostra a enorme importância dos pequenos possuidores de escravos. Esses eram, ao que parece, os senhores de escravos típicos, modais. Além disso, em várias regiões e períodos, a maior parte da população escrava pertencia a esses pequenos escravistas, e não a grandes proprietários.

Isso significa que, em tais regiões e períodos, a produção com trabalho escravo não se organizaria segundo o modelo tradicional da plantation. ${ }^{31} \mathrm{Na}$ ausência dessa forma de organização, seria de esperar, nessas regiões e períodos, que a aplicação de métodos coercitivos aos escravos não fosse uma prática corrente.

\footnotetext{
${ }^{28}$ Os autores mostraram que a proporção de escravos fora da região açucareira, em Pernambuco, era de $37 \%$, em 1842 , e $31 \%$, em 1872 .

${ }^{29}$ Versiani e Vergolino (2002 e 2003). Os dados básicos se originam de cerca de 1.600 inventários, provenientes de todas as regiões de Pernambuco, com informações sobre cerca de 10.500 escravos.

${ }^{30}$ A média ponderada da proporção de escravos em plantéis de até vinte, nas quatro regiões de Pernambuco (Mata, Agreste, Sertão e Recife) em 1850-1887, tomando como pesos as porcentagens da população escrava em cada região, no Censo de 1872, é 60,7\%. Dados cedidos por Versiani e Vergolino (amostra de 3.414 escravos em 538 inventários.)

${ }^{31}$ É comum a suposição de que tal modelo só era viável para plantéis maiores do que cerca de vinte escravos. Essa parecia ser a crença contemporânea nos Estados Unidos).
} 


\section{CONCLUSÃO}

Desenvolveram-se acima dois argumentos. Primeiro, que a tese de um tratamento dos escravos relativamente ameno, no caso brasileiro, pode ser melhor entendida à luz de proposições de teoria econômica relativas ao trabalho escravo. Sob esse prisma, a coerção aplicada à mão-de-obra escravizada - à parte as violências e crueldades a que deu origem — tem um significado econômico, como instrumento de maximização de produção, e só fará sentido quando for um meio eficaz para a consecução desse objetivo. Segundo, que em várias circunstâncias a coerção não é eficaz desse ponto de vista, e será preferível, para o senhor de escravos, a adoção de incentivos positivos em lugar de punições.

Em decorrência disso, a análise da ocorrência de circunstâncias que favorecessem ou não a adoção de métodos coercitivos dá pistas sobre a maior ou menor probabilidade de que os escravos fossem regularmente submetidos a castigos físicos ou à ameaça deles. É possível, em princípio, obter, a partir de tal análise, indicações objetivas quanto à forma provável de tratamento dos escravos, num dado contexto histórico.

A partir desse raciocínio, argumentou-se que as afirmativas de Gilberto Freyre sobre uma escravidão "benigna" referem-se, em geral, a situações em que o uso da coerção não seria, de fato, esperado.

No quadro geral do escravismo brasileiro, por outro lado, não é ainda possível fazer generalizações sobre a freqüência de configurações favoráveis a uma escravidão "branda". No entanto, há indícios crescentes na literatura recente de que a importância da escravidão de pequenos plantéis - em princípio incompatível com o uso sistemático de coerção como instrumento maximizador — tenha sido, no Brasil, bem maior do que se supunha. O cativo típico, em diversos locais e períodos, terá pertencido a um proprietário de poucos escravos, e não a um estabelecimento da grande lavoura. Haveria pouco espaço, nesses casos, para castigo e punições físicas como forma de controle da mão-de-obra.

Isto posto, parece claro que, no estado atual de conhecimento, a tese de que a escravidão brasileira tenha sido relativamente pouco coercitiva não pode ser descartada de forma simplista como mera manifestação de ideologia escravocrata ou resquício da propaganda antiabolicionista. A tese tem apoio conceitual na teoria econômica e, em várias situações, suporte empírico. Considerando a questão sob outro ângulo: pode-se hoje dizer que afirmativas genéricas na direção oposta - no sentido de que o tratamento de escravos, no Brasil, tivesse sido caracterizado pelo uso universal de força e violência física como forma de obter do escravo o desempenho desejado - são, à luz da evidência disponível, historicamente incorretas.

\section{REFERÊNCIAS BIBLIOGRÁFICAS}

BARICKMAN, B.J. A Babian Counterpoint; Sugar, Tobacco, Cassava, and Slavery in the Recôncavo, 1780-1860. Stanford: Stanford University Press, 1998. (Tradução brasileira: Um Contraponto Baiano. Rio de Janeiro: Civilização Brasileira, 2003). 
BARZEL, Yoram. “An Economic Analysis of Slavery," Journal of Law and Economics 20(1):87-110, Apr. 1977.

BASTIDE, Roger e FERNANDES, Florestan. Brancos e Negros em São Paulo. 2ed. São Paulo: Cia. Ed. Nacional, 1959.

BERGAD, Laird W. Slavery and the Demographic and Economic History of Minas Gerais, Brazil, 1720-1888. Cambridge: Cambridge University Press, 1999.

BURTON, Richard. Viagem do Rio de Janeiro a Morro Velho. [1869]. Trad. D. Jardim Júnior. Belo Horizonte: Itatiaia, 1976.

CARDOSO, Fernando Henrique. Capitalismo e Escravidão no Brasil Meridional; O Negro na Sociedade Escravocrata do Rio Grande do Sul. São Paulo: Difusão Européia do Livro: 1962.

CARDOSO, Fernando Henrique e IANNI, Octávio. Cor e Mobilidade Social em Florianópolis; Aspectos das Relações entre Negros e Brancos numa Comunidade do Brasil Meridional. São Paulo: Cia. Editora Nacional, 1960.

CHWE, Michael S. "Why Were Workers Whipped? Pain in a Principal-Agent Model." Economic Journal. 100:1109-1121, Dec. 1990.

CONRAD, Robert E. Children of God's Fire; A Documentary History of Brazilian Slavery. University Park: Pennsylvania State University Press, 1994.

COSTA, Emília Viotti da. Da Senzala à Colônia. São Paulo: Difusão Européia do Livro, 1966.

COSTA, Iraci del Nero da. Populações Mineiras. São Paulo: Instituto de Pesquisas Econômicas, 1981 (Ensaios Econômicos, $\mathrm{n}^{\circ}$ 7).

COSTA, Iraci del Nero da e NOZOE, Nelson H. "Elementos da Estrutura de Posse de Escravos em Lorena no Alvorecer do Século XIX.” Estudos Econômicos 19(2):319-345, 1989.

COUTY, Louis, A Escravidão no Brasil. [1881]. Trad. M.H. Rouanet. Rio de Janeiro: Fundação Casa de Rui Barbosa, 1988.

CRAWFORD, Stephen C. "Punishments and Rewards." Em: R.W. Fogel \& S. Engerman (eds.). Without Consent or Contract; Conditions of Slave Life and the Transition to Freedom. (Technical Papers, v. 2). New York: Norton, 1992.

ELKINS, Stanley M. Slavery; A Problem in American Institutional and Intellectual Life. 3 ed. Chicago: University of Chicago Press, 1976.

FENOALTEA, Stefano. "Slavery and Supervision in Comparative Perspective: a Model," Journal of Economic History 44(3):635-668, Sept. 1984.

FERNANDES, Florestan. A Integração do Negro na Sociedade de Classes. 2v. São Paulo: DominusEDUSP, 1965.

FINDLAY, Ronald. "Slavery, Incentives, and Manumission: a Theoretical Model," Journal of Political Economy 83(5):923-33, Sept./Oct. 1975.

FOGEL, Robert W. e ENGERMAN, Stanley L. Time on the Cross. 2v. Boston: Little, Brown \& Co., 1974.

FREYRE, Gilberto. Vida Social no Brasil nos Meados do Século XIX. [1922]. Recife: Instituto Joaquim Nabuco de Pesquisas Sociais, 1964.

FREYRE, Gilberto. Casa Grande \& Senzala; Formação da Família Brasileira sob o Regime da Economia Patriarcal. [1933]. 21 ed. Rio de Janeiro: José Olympio, 1981.

FREYRE, Gilberto. Sobrados e Mucambos; Decadência do Patriarcado Rural e Formação do Urbano. [1936]. 9 ed. Rio de Janeiro: Record, 1996.

FREYRE, Gilberto. Nordeste; Aspectos da Influência da Cana sobre a Vida e a Paisagem do Nordeste do Brasil. Rio de Janeiro: José Olympio, 1937.

FURTADO, Celso. Formação Econômica do Brasil. [1959]. São Paulo: Cia. Editora Nacional, 1976.

GENOVESE, Eugene D. Roll, Jordan, Roll; The World the Slaves Made. New York: Vintage Books, 1976.

GORENDER, Jacob. O Escravismo Colonial. 3 ed. São Paulo: Ática 1980.

HILLIER, Brian. The Economics of Asymmetric Information. London: Macmillan Press, 1997.

IANNI, Octavio. As Metamorfoses do Escravo; Apogeu e Crise da Escravatura no Brasil Meridional. São Paulo: Difusão Européia do Livro, 1962.

IANNI, Octávio. Escravidão e Racismo. 2 ed. S. Paulo: Hucitec, 1988. 
KAHN, Charles. "An Agency Approach to Slave Punishments and Awards." Em: R.W. Fogel \& S. Engerman (eds.). Without Consent or Contract; Conditions of Slave Life and the Transition to Freedom. (Technical Papers, v. 2). New York: Norton, 1992.

KOSTER, Henry. Viagens ao Nordeste do Brasil. [1816] Trad. e notas: Luiz da Câmara Cascudo. São Paulo: Cia. Editora Nacional, 1942.

LUNA, Francisco Vidal. Minas Gerais: Escravos e Senhores; Análise da Estrutura Populacional e Econômica de Alguns Centros Mineratórios (1718-1804). São Paulo: Instituto de Pesquisas Econômicas, 1981.

LUNA, Francisco Vidal. "Estrutura da Posse de Escravos em Minas Gerais (1718)”. Em: Antônio E.M. Barreto et al. História Econômica: Ensaios. São Paulo: Instituto de Pesquisas Econômicas, 1983.

LUNA, Francisco Vidal. "Estrutura de Posse de Escravos e Atividades Produtivas em Jacareí (1777 a 1829)." Revista do Instituto de Estudos Brasileiros 28:23-35, 1988.

LUNA, Francisco Vidal. "São Paulo: População, Atividades e Posse de Escravos em Vinte e Cinco Localidades (1777- 1829).” Estudos Econômicos 28(1):99-169, jan./mar. 1998.

LUNA, Francisco Vidal \& COSTA, Iraci del Nero da. "Posse de Escravos em São Paulo no Início do Século XIX.” Estudos Econômicos 13(1):211-221, jan./abr. 1983.

LUNA, Francisco Vidal \& KLEIN, Herbert S. Slavery and the Economy of São Paulo, 1750-1850. Stanford: Stanford University Press, 2003.

MARCONDES, Renato L. “A Pequena e a Média Propriedade na Grande Lavoura Cafeeira do Vale do Paraíba." Locus: Revista de História (Juiz de Fora) 4(2):35-54, 1998.

MARCONDES, Renato L. "A Propriedade Escrava no Vale do Paraíba Paulista durante a Década de 1870.” Estudos de História 29:51-74, 2002.

MARQUESE, Rafael B. Feitores do Corpo, Missionários da Mente; Senhores, Letrados e o Controle dos Escravos nas Américas, 1660-1860. São Paulo: Companhia das Letras, 2004.

MOTTA, José Flávio. Corpos Escravos, Vontades Livres; Posse de Cativos e Família Escrava em Bananal (1801-1829). São Paulo: FAPESP-Annablume, 1999.

NABUCO, Joaquim. O Abolicionismo. [1883]. Petrópolis: Vozes, 1988

NABUCO, Joaquim. Minha Formação. [1900]. Brasília: Senado Federal, 2001. Coleção Biblioteca Básica Brasileira.

OliVEIRA LIMA, M. de. Pernambuco; seu Desenvolvimento Histórico. [1895]. 3 ed.(facsimilar). Recife: Massangana, 1997.

PAIVA, Clotilde Andrade. População e Economia nas Minas Gerais do Século XIX. Tese de Doutoramento. São Paulo: Faculdade de Filosofia, Letras e Ciências Humanas da Universidade de São Paulo, 1996.

PASSOS SUBRINHO, Josué M. Reordenamento do Trabalho; Trabalho Escravo e Trabalho Livre no Nordeste Açucareiro; Sergipe, 1850-1930. Aracaju: Funcaju, 2000.

PHILLIPS, Ulrich B. American Negro Slavery. [1918]. Baton Rouge: Louisiana State University Press, 1966.

RIBEIRO, Darcy. "Gilberto Freyre: uma Introdução a Casa Grande \& Senzala”. Em: Sobre o Óbvio. Rio de Janeiro: Ed. Guanabara, 1986.

RIBEIRO, Darcy. O Povo Brasileiro; A Formação e o Sentido do Brasil. Rio de Janeiro: Companhia das Letras, 1995.

RUGENDAS, J. M. Viagem Pitoresca através do Brasil. [1835]. Trad. S. Milliet. Belo Horizonte: Itatiaia, 1975.

SAINT-HILAIRE, Auguste de. Viagem pelas Províncias do Rio de Janeiro e Minas Gerais. [1830]. Trad. V. Moreira. Belo Horizonte: Itatiaia, 1975.

SAINT-HILAIRE, Auguste de. Viagem a Curitiba e Santa Catarina. [1851]. Trad. R.R. Junqueira. Belo Horizonte: Itatiaia, 1978.

SCHWARTZ, Stuart B. "Patterns of Slaveholding in the Americas: New Evidence from Brazil." American Historical Review 87(1):55-86, Feb. 1982.

SCHWARTZ, Stuart B. Sugar Plantations in the Formation of Brazilian Society; Bahia, 1550-1835. Cambridge: Cambridge University Press, 1985. 
SIMONSEN, Roberto C. História Econômica do Brasil (1500/1820). [1937]. 7 ed. São Paulo: Cia. Ed. Nacional; Brasília: INL/MEC, 1977.

STAMPP, Kenneth M. The Peculiar Institution; Slavery in the Ante-Bellum South. New York: Vintage Books, 1956.

TANNENBAUM, Frank. Slave and Citizen; the Negro in the Americas. New York: Knopf, 1947.

VERSIANI, Flávio Rabelo. "Brazilian Slavery: toward an Economic Analysis." Revista Brasileira de Economia 48(4): 463-478, out./dez. 1994.

VERSIANI, Flávio Rabelo. "Os Escravos que Saint-Hilaire Viu.” História Econômica e História de Empresas 3(1):7-42, 2000.

VERSIANI, Flávio Rabelo e VERGOLINO, José Raimundo O. "Slave Holdings in Nineteenth-Century Brazilian Northeast: Sugar Estates and The Backlands”. XIII Congress of the International Economic History Association, Buenos Aires, 22-26 de julho de 2002

VERSIANI, Flávio Rabelo e VERGOLINO, José Raimundo O. "Posse de Escravos e Estrutura da Riqueza no Agreste e Sertão de Pernambuco, 1777-1887”. Estudos Econômicos 33(2):353-393, abr./jun. 2003. 